\title{
Effectiveness of two field methods of saturating near surface concrete on the water permeability of in situ concrete
}

\author{
Kai Yang ${ }^{1}$, Muhammed Basheer ${ }^{*}$, Sreejith Nanukuttan ${ }^{2}$, Yun Bai $^{3}$, Adrian Long ${ }^{2}$ \\ ${ }^{1}$ School of Civil Engineering, University of Leeds, Leeds, UK \\ ${ }^{2}$ School of Natural and Built Environment, Queen's University Belfast, Belfast, UK \\ ${ }^{3}$ Civil, Environmental and Geomatic Engineering, University College London, London, UK
}

\begin{abstract}
Determining the water permeability of concrete in structures remains a challenge because of difficulties in removing the influence of its moisture content. Saturating concrete with water could be one option, but this is not easy to achieve on site. This paper reports a testing programme carried out to assess the reliability and effectiveness of two field saturation methods, viz. vacuum saturation and ponding. The water permeability test results after applying the vacuum saturation and ponding were compared with that obtained after incremental immersion. It was found that ponding was unable to remove the influence of moisture, whilst vacuum saturation was effective for wet concretes. The results obtained from the electrical resistance measurements after incremental immersion suggested that the water permeability of concretes can be accurately determined by carrying out in situ permeability tests if the near surface region up to a depth of $25 \mathrm{~mm}$ is fully saturated.
\end{abstract}

\section{Introduction}

Concrete has the reputation as a strong and durable material $[1,2]$. However, the occurrence of durability problems and some catastrophic failures of reinforced concrete structures since 1970's have caused deep concerns to civil engineers in their ability to design and construct durable reinforced concrete structures [3]. Since then numerous approaches have been proposed to assess the durability of concrete.

The permeability of cover concrete has been considered as a key parameter to assess the durability of concrete structures and numerous methods for measuring the in situ permeation properties of normal concretes have been proposed [4-6]. However, they are not effective for distinguishing the permeation characteristics of very low permeability concretes, such as those typically associated with high-performance concrete (HPC), because of their low sensitivity to variations in permeation characteristics. Against this background, a new air permeability test and a water permeability test were developed to ensure that the differences between HPCs can clearly and reliably be identified [7].

For most field permeability assessments, a technical barrier is that the results are significantly affected by the moisture content of the concrete $[8,9]$. An investigation by Yang et al. has indicated that to remove the influence of moisture on air permeability of HPCs, the relative humidity in the near-surface region (from surface to 20 $\mathrm{mm}$ depth) should be less than $60 \%$ [7] as opposed to the value of $80 \%$ proposed by Basheer and Nolan for NCs [10]. As this moisture condition is not easy to reach for HPCs on site, an alternative could be to measure their permeation properties by carrying out in situ water permeability tests.

In situ water permeability tests are usually carried out when the concrete is in a fully saturated state. However, relatively few publications have been found to deal with the influence of moisture on water permeability tests. For the Clam Water permeability test [11], the test area is saturated for 24 hours by ponding water before carrying out the test, but this approach is not effective to achieve the saturated state for dense concretes (e.g. w/c $<0.5$ ). Whiting attempted to saturate concrete using a similar technique, as part of the on-site Rapid Chloride Permeability Test [12]. However, it can be noted that only normal concretes were tested in their research. In the case of HPCs, almost no investigations on the effect of moisture on in situ water permeability tests can be found. Furthermore, studies do not give any detailed information on the effectiveness of vacuum saturation and, hence, the preconditioning procedures are not fully understood. Therefore, the in situ procedures for vacuum saturation have to be developed for HPCs.

In this study, three saturation regimes were selected, including vacuum saturation, ponding and incremental immersion. The vacuum saturation and ponding are considered as possible approaches for field use, whilst the incremental immersion is considered as the 'reference' method, as the previous work [13] has shown that reliable water permeability results can be obtained after incremental immersion of HPCs.

\section{Experimental programme}

\footnotetext{
* Corresponding author: Muhammed Basheer, School of Civil Engineering, University of Leeds, Email: p.a.m.basheer@leeds.ac.uk
} 


\subsection{Materials and concrete mix proportions}

In the context of this research, HPCs refer to concretes with low permeation properties. Details of mix proportions of the three HPCs are given in Table 1. CEMI cement conforming to BS-EN 197 and two supplementary cementitious materials (SCMs), viz. microsilica (MS) and pulverised fuel ash (PFA), were used in this study. The PFA, conforming to BS-EN 450, was obtained from Kilroot Power station in Northern Ireland, UK and microsilica, conforming to BS-EN 13263-1, was used in slurry form which was supplied by Elkem. A polycarboxylic acid based superplasticiser was used to maintain the required consistence.

Table 1. Concrete mix proportions and both fresh properties and compressive strength.

\begin{tabular}{|c|c|c|c|}
\hline Concrete & PFA & PC & MF \\
\hline Water $\left(\mathrm{kg} / \mathrm{m}^{3}\right)$ & 145 & 145 & 145 \\
\hline Portland cement $\left(\mathrm{kg} / \mathrm{m}^{3}\right)$ & 388 & 485 & 449 \\
\hline Microsilica $\left(\mathrm{kg} / \mathrm{m}^{3}\right)$ & 0 & 0 & 36 \\
\hline PFA $\left(\mathrm{kg} / \mathrm{m}^{3}\right)$ & 97 & 0 & 97 \\
\hline Sand $\left(\mathrm{kg} / \mathrm{m}^{3}\right)$ & 668 & 689 & 652 \\
\hline Coarse aggregate $\left(\mathrm{kg} / \mathrm{m}^{3}\right)$ & 1150 & 1150 & 1150 \\
\hline $\begin{array}{c}\text { Superplasticiser }(\% \text { of } \\
\text { binder content) }\end{array}$ & 1.4 & 1.3 & 1.5 \\
\hline Air content $(\%)$ & 0.6 & 1.0 & 1.6 \\
\hline Slump $(\mathrm{mm})$ & 220 & 225 & 240 \\
\hline $\begin{array}{c}28 \text { day compressive } \\
\text { strength }(\mathrm{MPa})\end{array}$ & 81.3 & 81.8 & 84.2 \\
\hline
\end{tabular}

The fine aggregate was medium graded natural sand and the coarse aggregate was crushed basalt with $10 \mathrm{~mm}$ and $20 \mathrm{~mm}$ size proportioned at equal mass. Before casting, the aggregates were dried in an oven at 105 $( \pm 5)^{\circ} \mathrm{C}$ for 24 hours followed by cooling to $20( \pm 1)^{\circ} \mathrm{C}$ for one day to control the moisture content.

\subsection{Preparation of specimens}

The concrete was mixed in accordance with BS 1881: part 125 and the fresh concrete was assessed for slump and air content according to BS-EN 12350-2 and BS-EN 123507 respectively. For each concrete mix, $410 \times 100 \times 250 \mathrm{~mm}$ blocks were cast for carrying out the water permeability test and $100 \mathrm{~mm}$ cubes for determining the compressive strength at the age of 28 days. The slab specimens contained an electrode array for resistance measurements. After casting, the specimens were covered with wet hessian and placed in a constant temperature and relative humidity room at $18( \pm 2)^{\circ} \mathrm{C}$ and $60( \pm 10) \%$ respectively so that all specimens had similar environmental conditions during their initial period of curing. The fresh properties and the compressive strength values for each concrete are reported in Table 1.

\subsection{Test methods}

\subsubsection{High pressure water permeability test}

A high pressure water permeability test setup was used in this study, details of which and the test procedure are available in Yang et al. [7]. To carry out the test, the test head was clamped on the surface of the specimen, which was then connected to an air compressor for pressurising the testing system. During measurements, the pressure was maintained at 7 bar by advancing a piston through a cylinder. The volume of water within the cylinder was recorded every minute. Each measurement took 120 minutes.

\subsubsection{Electrical resistance measurement}

Electrical resistance measurements were carried out in order to monitor variations in the degree of saturation within the cover region. The stainless steel rods were placed at depths of 10,15,20,25,30mm from the surface, which is the same as that used by McCarter et al. [14]. The changes in electrical resistance with time across each electrode pair were measured by an LCR meter and recorded by a data logging system.

\subsubsection{Vacuum saturation setup}

Figure 1 illustrates the vacuum saturation setup. The design concept of the vacuum saturation set-up used in this study was based on Whiting's work [12] and that used in some other surface permeability tests [15]. The vacuum pressure was controlled by a regulator and the change in vacuum level in the chamber was monitored using a vacuum pressure gauge.

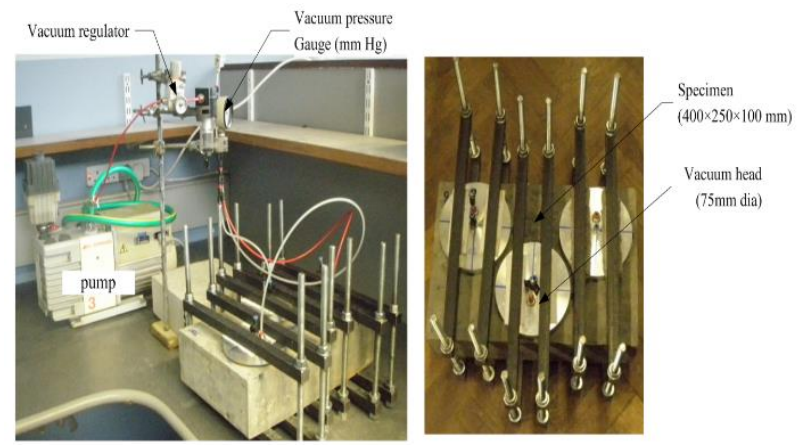

(a) Vacuum set up (b) Vaccum ring

Fig. 1. The vacuum saturation set-up.

Two levels of vacuum (40 and $240 \mathrm{~mm} \mathrm{Hg}$ ) and two duration of application ( 3 and 6 hour) were chosen as the test variables. These are denoted as V40-3, V240-3, V406 and V240-6 whilst reporting the results. After setting up the vacuum saturation system, the vacuum pump was switched on and the vacuum pressure was adjusted to the desired level of vacuum for the two duration of vacuum application using the regulator. The pressure level was monitored by the gauge and adjusted, if necessary. At the end of the two specified periods of vacuum application, water was admitted into the chamber. After filling the 
saturation head, vacuum was released so that the specimen would admit water for another 40 hours. The water permeability test was then performed at this location.

\section{Results and discussion}

\subsection{Investigation of the effectiveness of vacuum saturation}

\subsubsection{The possibility of achieving the 'steady-state' after vacuum saturation}

Figure 2 shows the water flow into the concrete blocks after the four different vacuum saturation regimes at five different locations. The behaviour of the water flow was examined before attempting further interpretation because the new water permeability test is based on the steadystate flow theory. The duration to reach a 'steady-state' as well as the rate of flow were determined, the procedure of which is similar to that reported in the previous publication [6]. It is evident that the relationship between the volume of in-flow and time is non-linear in all cases, especially during the initial period. Further, there was a test outlier in both V40-3 and V240-3 and two test outliers in V240-6. These data indicate that either the test location was not properly saturated or the ring was not properly fixed on the test surface, hence they were not used in any further analysis.

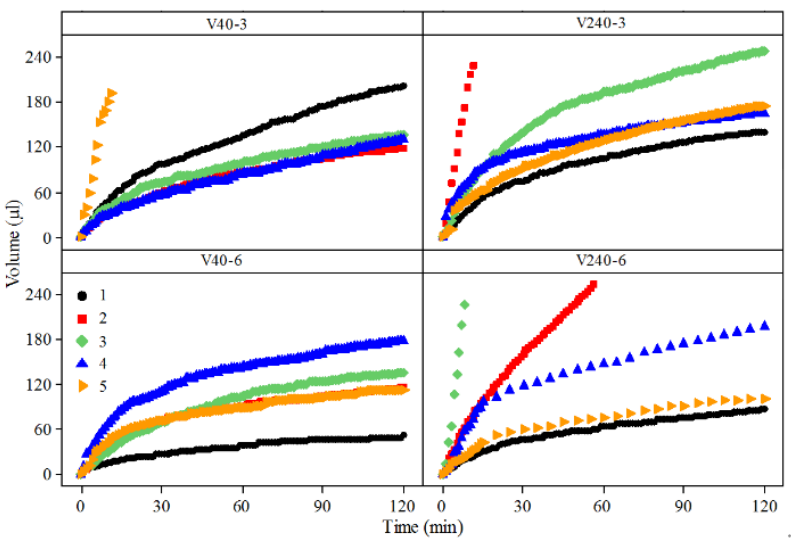

Fig. 2. Water permeability test data after vacuum saturation of the MF concrete

The flowrates at different test duration were estimated using the regression analysis of the volume of water versus time. These results indicated that the flowrates decreased as time increased, and stabilised after 60 minutes. Therefore, the flowrates for all tests were estimated based on the regression analysis of the data after 60 minutes.

\subsubsection{The effect of vacuum pressure and duration of vacuum application}

The effect of vacuum pressure and duration of vacuum on the steady-state flowrate was analysed through a $2^{2}$ factorial experiment. Table 2 summarises the results of the statistical analysis and Figure 3 shows the main effects of the factors and the interaction between vacuum pressure and vacuum duration. As can be seen from the table, only the effect of vacuum duration is significant, whilst the others do not remarkably affect the flowrate. In Figure 3, it can be seen that the vacuum duration had a negative contribution on the response, meaning that a higher level leads to a lower flowrate. This can be expected because longer duration can remove the air effectively and more pores can become saturated, hence giving a lower flowrate. Furthermore, the increase of the vacuum pressure can be seen to cause an increase in the flowrates.

Although Figure 3 demonstrates the existence of interaction between the vacuum pressure and the duration of vacuum application, Table 2 shows that this is not significant. Therefore, the vacuum level and its duration can be decided based on their main effects. In other words, a lower vacuum pressure and longer vacuum duration are preferable for field applications to achieve the steady state of flow.

Table 2 The analysis of variance of the $2^{2}$ factorial experiment

\begin{tabular}{c|c|c|c|c}
\hline Factor & $\begin{array}{c}\text { Sum of } \\
\text { square }\end{array}$ & DoE & $\begin{array}{c}\text { Mean } \\
\text { square }\end{array}$ & $\begin{array}{c}\text { p- } \\
\text { value* }\end{array}$ \\
\hline Vacuum pressure & 0.0062 & 1 & 0.0062 & 0.637 \\
\hline Duration & 0.147 & 1 & 0.147 & 0.036 \\
\hline $\begin{array}{c}\text { Vacuum } \\
\text { pressurexDuration }\end{array}$ & 0.0258 & 1 & 0.0258 & 0.342 \\
\hline Error & 0.316 & 12 & 0.0263 & \\
\hline Total & 0.522 & 15 & & \\
\hline
\end{tabular}

*Note: $\mathrm{p}$-value $<0.01$ means highly significant, $0.05<\mathrm{p}$-value $<0.01$ means significant, $p$-value $>0.05$ means nonsignificant.
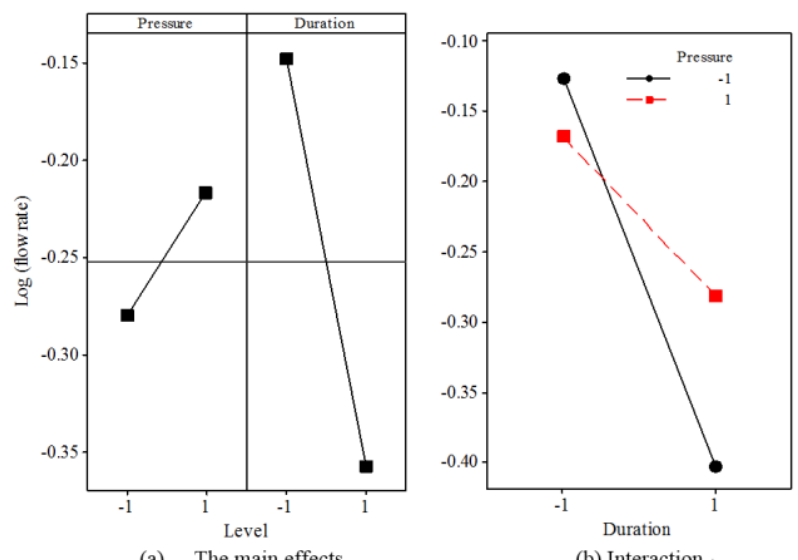

(a) The main effects

(b) Interaction

Fig. 3. The plots of main effects and interaction

\subsection{Investigation of the effectiveness of ponding}

Ponding the test area with water was another approach that was investigated to saturate concrete on site and, hence, its influence on water permeability results was assessed. The test head that was described in section 2.3.3 was clamped on the concrete surface and water was filled in the head (termed as ponding with water). After 48hours of ponding, the new water permeability test was 
carried out at the conditioned region and the volume of water transported into the concrete at different duration determined. From these data the flowrate was obtained, as was done for the vacuum saturation method. The flowrate corresponding to the steady state is presented in Figure 4, along with those from the four combinations of vacuum saturation method and the incremental immersion of test specimens for 6 and 10 days. [The incremental immersion, principally reported by researchers from Queen's University Belfast [16], was a method to saturate concrete samples in the laboratory. The incremental immersion method is able to remove air in specimens by leaving one surface exposed to the ambient whilst water is absorbed through other surfaces; this enables almost $100 \%$ degree of saturation. According to results obtained previously $[11,17]$, this method could give results similar to that obtained from the vacuum saturation method.

It can be seen from Figure 4 that the flowrate after ponding is roughly three times of what was obtained after the vacuum saturation. This is because ponding is known to be effective only to saturate the near surface region, typically up to 1 to $2 \mathrm{~mm}$ [18], which is lower than the effective depth in the water permeability test (typically 25 $\mathrm{mm}$ ). Therefore, it can be concluded that ponding is not an effective saturation method for the steady state water permeability tests on HPCs.

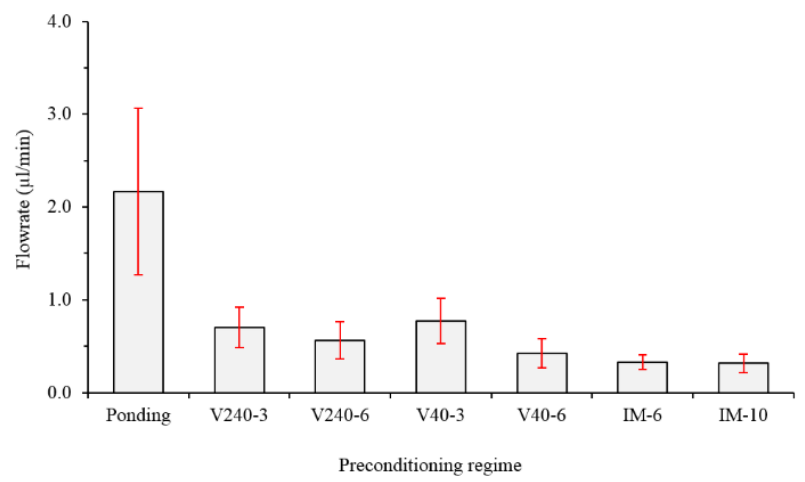

Fig. 4. Flowrates of the new water permeability tests after incremental immersion, ponding and vacuum saturation

\subsection{Comparison of the flowrates for vacuum saturation and incremental immersion}

The effectiveness of both the vacuum saturation and ponding to remove the influence of moisture in the cover concrete on the water permeability test was further examined by comparing the flowrates in these cases with that obtained for the two incremental immersion periods, viz. 6 days and 10 days (Figure 4). A comparison between the two duration of incremental immersion was also made in order to establish whether or not the duration of immersion had any significant effect on the flowrate. The mean values in Figure 4 are cross-compared using the least significant difference (LSD) [19] and the results are summarised in Table 3. The reason for comparing the mean flowrates of both the ponding and the vacuum saturation conditions (V-240-3, V240-6, V40-3 and V406 ) with that for the incremental immersion for 6 days (IM$6)$ in this table is given below.
In Figure 4, three features can be identified. Firstly, the flowrates after incremental immersion are the lowest (IM-6 and IM-10 in Figure 4) and no obvious difference existed between 6 days and 10 days of immersion. The data in Table 3 show that the difference between the means for these two test conditions is not significant. Therefore, the effectiveness of other saturation methods can be assessed by comparing with the flowrate for either of these two; hence, hereafter the comparison is made with data from incremental immersion for 6 days (IM-6).

Secondly, there is noticeable difference in flowrate between incremental immersion and ponding (Figure 4). The data in Table 3 highlights that this difference is highly significant.

Thirdly, as the vacuum level was decreased from 240 $\mathrm{mmHg}$ to $40 \mathrm{mmHg}$ and the duration of vacuum application was increased from 3 hours to 6 hours, the flowrate decreased. Further, the $40 \mathrm{mmHg}-6$ hour vacuum saturation regime gave similar flowrate to that of the incremental immersion and the data in Table 3 confirms that the difference between the mean flowrates for these two test conditions was not significant. However, this is not the case for other treatment combinations.

Therefore, it has been concluded that vacuum saturation with the application of the lower vacuum pressure $(40 \mathrm{mmHg})$ and the longer duration (6 hours) is adequate to remove the influence of variations in moisture on the steady state water permeability test and ponding for 48 hours is not sufficient to achieve this.

Table 3 Summary of cross-comparison of the flowrates determined from the new water permeability tests after different preconditioning regimes

\begin{tabular}{c|c|c|c|c}
\hline $\begin{array}{c}\text { Saturation } \\
\text { method }\end{array}$ & $\begin{array}{c}\text { Comparis } \\
\text { on }\end{array}$ & $\begin{array}{c}\text { Mean } \\
\text { difference }\end{array}$ & DoE & P-value* \\
\hline Ponding & $\begin{array}{c}\text { Ponding } \\
\text { vs IM-6 }\end{array}$ & 0.802 & 1 & $<0.0001$ \\
\hline V240-3 & $\begin{array}{c}\text { V240-3 } \\
\text { vs IM-6 }\end{array}$ & 0.327 & 1 & 0.0036 \\
\hline V240-6 & $\begin{array}{c}\text { V240-6 } \\
\text { vs IM-6 }\end{array}$ & 0.227 & 1 & 0.0347 \\
\hline V40-3 & $\begin{array}{c}\text { V40-3 vs } \\
\text { IM-6 }\end{array}$ & 0.368 & 1 & 0.0013 \\
\hline V40-6 & $\begin{array}{c}\text { V40-6 vs } \\
\text { IM-6 }\end{array}$ & 0.092 & 1 & 0.3441 \\
\hline IM-6 & $\begin{array}{c}\text { IM-6 vs } \\
\text { IM-10 }\end{array}$ & 0.025 & 1 & 0.7961 \\
\hline
\end{tabular}

*Note: -value $<0.01$ means highly significant, $0.05<$ p-value $<0.01$ means significant, $\mathrm{p}$-value $>0.05$ means nonsignificant.

\subsection{Confirmation of the effectiveness of the proposed vacuum saturation regime}

Despite the similarities in flowrates between vacuum saturation and incremental immersion, there is a potential risk to draw an improper conclusion. To see if the effect of mixes on water flowrates determined by using the vacuum saturation method is similar to that from the incremental immersion method, the flowrates for the two methods of saturating three concrete mixes were obtained and compared in Figure 5. It can be seen that the flowrates after vacuum saturation are similar to those after 
incremental immersion, albeit the vacuum saturation offering slightly higher value for all the mixes. However, the t-test [19] for comparing the flowrates (Table 4) shows that the difference between the flowrates for the two precondition regimes is not statistically significant. That is, the proposed vacuum saturation regime is sufficient to achieve steady state permeability values similar to that for the incremental immersion.

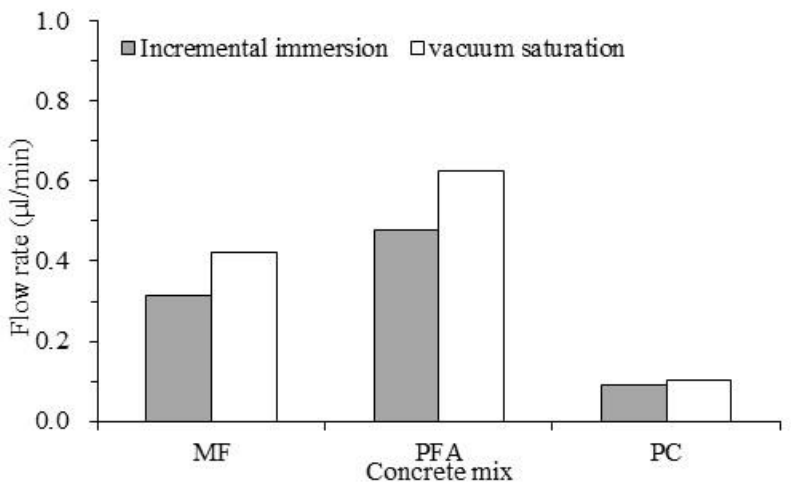

Fig. 5. Comparison of flowrates after saturating by incremental immersion and vacuum saturation for three different concrete mixes

Table 4 Summary of the results of the paired t-test between incremental immersion and vacuum saturation for PFA and PC

\begin{tabular}{c|c|c}
\hline t-test & $\begin{array}{c}\text { PFA incremental } \\
\text { immersion Vs } \\
\text { Vacuum saturation }\end{array}$ & $\begin{array}{c}\text { PC incremental } \\
\text { immersion Vs } \\
\text { Vacuum saturation }\end{array}$ \\
\hline$\sigma^{*}{ }_{\mathrm{d}}$ & 0.087 & 0.053 \\
\hline $\mathrm{t}_{0.05} /(\mathrm{n}-1)^{0.5}$ & 0.338 & 0.274 \\
\hline $\mathrm{t}_{0.01} /(\mathrm{n}-1)^{0.5}$ & 1.676 & 0.953 \\
\hline $\mathrm{A}_{0.05}$ & 0.322 & 1.676 \\
\hline $\mathrm{A}_{0.01}$ & 0.566 & 0.261 \\
\hline Conclusion & Non-significant & Non-significant \\
\hline
\end{tabular}

Although the objective of the research reported in this paper was not to compare the water permeability of different HPCs, but to evaluate the preconditioning regimes for carrying out the steady state water permeability tests on HPCs, it is important to highlight here that the PC mix had the lowest flowrate in comparison with the PFA and MF mixes. Most classical concrete technology books state that the use of SCMs can give a lower permeability, provided samples are cured under a suitable condition [2, 20]. This apparent anomaly might have been caused by the effect of different degrees of compaction of the three HPCs on their pore structure characteristics and transport properties, as highlighted by Banthia et al. [21]. However, the results in Figure 5 would suggest that, even though SCMs could be used to produce a potentially lower permeability concrete, this cannot be guaranteed for all manufacturing and exposure conditions. Therefore, direct on site measurements of concrete permeability are strongly recommended. The results also highlight that the proposed test method is able to identify the differences caused by these factors.

\subsection{Requirements to obtain reliable water permeability results}

It is necessary to specify the requirements to yield a reliable measurement for field applications. Provided the results after incremental immersion are considered as the 'reference' data, the moisture condition after other saturation techniques should be identical for achieving similar results. The saturation degree is the ideal parameter to describe this feature and the method proposed using the Archie's law [22] was used to estimate the degree of saturation in this study:

$S=\left(\frac{R_{O}}{R_{t}}\right)^{\frac{1}{m}} \times 100 \%$

where $S$ denotes the saturation degree of the pore system $(\%), R_{o}$ denotes the resistance at the saturation condition $(\Omega), R_{t}$ denotes the resistance at the time of measurement $(\Omega), m$ denotes the cementation factor reflecting the tortuous nature of the capillary pores.

To evaluate the value of saturation degree, $R_{o}$ and $m$ in Equation (1) need to be determined. A fully saturated condition is difficult to reach and, hence, the samples were immersed for 50 days (leaving one surface exposed to surface) and the resistance was measured to obtain $R_{o}$. For the value of ' $m$ ', it is generally in the range of 1.5 to 3 [23] and a middle value, 2, was used in this case.

Figure 6 shows the saturation degree for the different conditions, viz. after drying before immersion (AD), incremental immersion (IM, 6 days and 10 days respectively) and vacuum saturation (VS). As expected, the saturation degree after VS is generally higher than that of $\mathrm{AD}$, especially at the surface region (around $20 \mathrm{~mm}$ ). Meanwhile, the saturation degree after VS was lower than those after the two IMs. These results show the reason why the proposed vacuum saturation procedure was not as effective as the incremental immersion. Furthermore, the surface region, approximately 20 to $25 \mathrm{~mm}$, achieved a higher degree of saturation (higher than 95\%) after incremental immersion. This moisture condition can be considered as the requirement for the proposed steady state water permeability test, as there is a concentration of flow paths located within this region (confirmed by experiments $[12,24]$.

\section{Conclusions}

1) The vacuum saturation gives statistically similar results compared with results after incremental immersion when the moisture content inside the concrete is high. To remove the influence of moisture on permeability tests, only the low level of vacuum (40 $\mathrm{mm} \mathrm{Hg}$ ) and the long duration (6 hours) is effective.

2) Ponding for 48 hours before carrying out the new water permeability test is insufficient to remove the influence of moisture, as the flowrates of the new 
water permeability test after ponding are approximately 3 times greater than after incremental immersion, which is mainly attributed to the fact that only the surface region (typically 1-2 mm) was saturated.

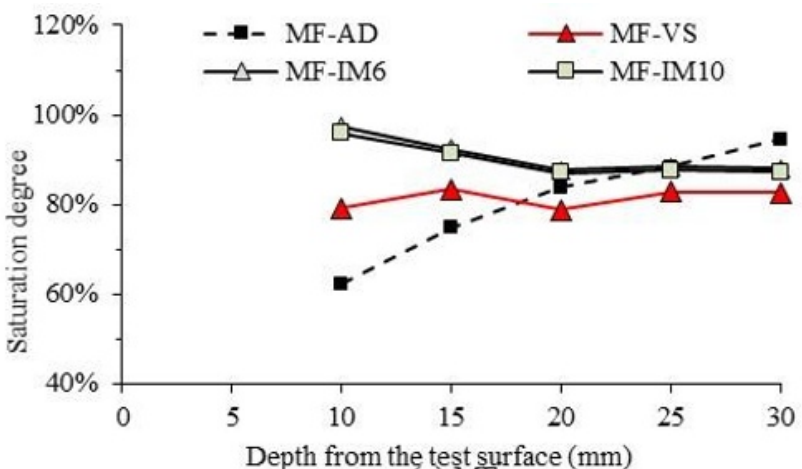

(a) MF

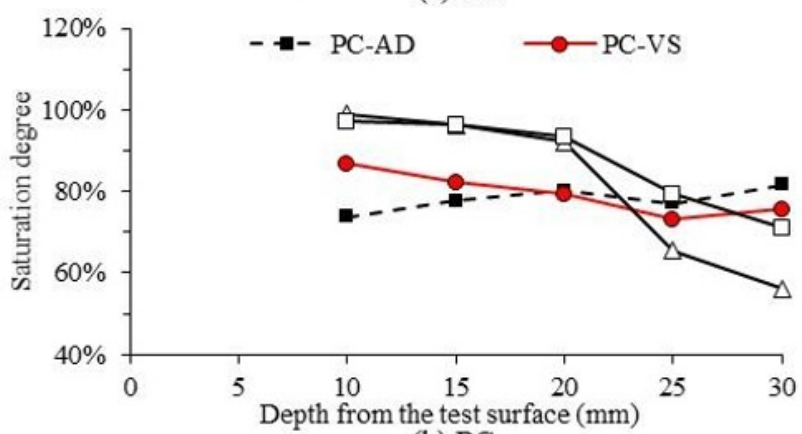

(b) PC

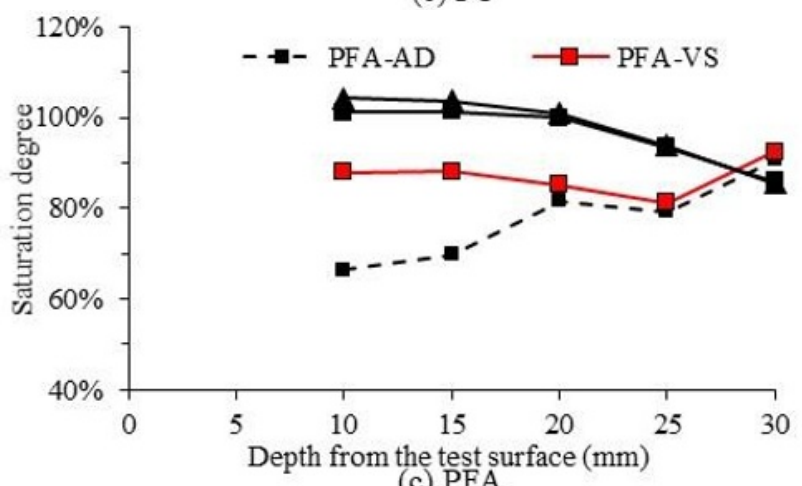

(c) PFA

Fig. 6. Comparison of the saturation degree between vacuum saturation and incremental immersion

3) The results indicate that the test region up to a depth of $25 \mathrm{~mm}$ should be saturated for performing reliable site water permeability tests.

4) The permeability of HPCs is a complicated function of many factors, especially it is sensitive to the construction practice, curing regime and mix proportion. Therefore, direct measurements of permeability on site are highly recommended and the new test method could be a potential technique for this purpose.

\section{References}

1. S.A. Barbhuiya, P.A.M. Basheer, G.I.B. Rankin, M.W. Clark. Concrete in aggressive aqueous environments - Performance, Testing, and Modelling: RILEM Publications SARL (2009).
2. P.K. Mehta, P.J.M. Monteiro. Concrete: Microstructure, Properties, and Materials. McGraw Hill Professional, (2005).

3. S.C. Pattanaik, E. Gopalkrishnan, S.K. Patro. The Indian. Conc. J. (2015).

4. J.H. Bungey, Constr. and Bldg. Mater. 18, (2004).

5. M.Q. Zhong, C. Wang, C.H. Yang, Y. Tang, R.Y. Wang, Technical report on the Properties of Concrete and Countermeasures for Bridge Engineering. Chongqing: Department of Transport; (2012)

6. K. Yang, P.A.M. Basheer, Y. Bai, B.J. Magee, A.E. Long, Mater. and Struct. 48, (2015).

7. K. Yang, P.A.M. Basheer, Y. Bai, B.J. Magee, A.E. Long. NDT \& E Int. 64, (2014).

8. R.T. Torrent, M.G. Alexander, J. Kropp. NonDestructive Evaluation of the Penetrability and Thickness of the Concrete Cover RILEM TC 189. NEC: State-of-the-Art Report: RILEM (2007).

9. P.A.M. Basheer. Handbook of Analytical Techniques in Concrete Science and Technology: Principles, Techniques and Applications, Noyes Publications, (2001).

10. P.A.M. Basheer, E.A. Nolan. Constr. and Bldg. Mater. 15, (2001).

11. P.A.M. Basheer, R. Montgomery, A.E. Long. NDT \& E Int. 12, (1995).

12. D. Whiting, FHWA/RD-81/119: Federal Highway Administration, (1981)

13. K. Yang, P.A.M. Basheer, B. Magee, Y. Bai, A.E. Long. J Mater. Civ. Eng. 27, (2015).

14. W.J. McCarter, B. Suryanto, H.M. Taha, S. Nanukuttan, P.A.M. Basheer. J Struct. Inte. Maint. 2, (2017)

15. K. Schonlin, H.K. Hilsdorf. Concrete Durability ACI, (1987).

16. A. Elahi, P.A.M. Basheer, S. Nanukuttan, Q.U.Z. Khan. Constr. and Bldg. Mater. 24, (2010).

17. P.A.M. Basheer, F.R. Montgomery, A.E. Long. Proc. ICE Struct. Bldg. 104, (1994).

18. J. Kim, W.J. McCarter, B. Suryanto, S. Nanukuttan, P.A.M. Basheer, T.M. Chrisp. Cem. Concr. Comp. 72, (2016).

19. D.C. Montgomery. Statistical quality control: A modern introduction. Oxford, England, Wiley, (2009).

20. A.M. Neville. Properties of concrete. Pearson, (1995).

21. N. Banthia, M. Pigeon, J. Marchand, J. Boisvert. J Mater. Civ. Eng. 4, (1992).

22. M.R. Nokken, R.D. Hooton. Mater. Struct. 41, (2007)

23. W.J. McCarter, T.M. Chrisp, G. Starrs, P.A.M. Basheer, S. Nanukuttan, S. Srinivasan. Int. J Struct. Eng. 6, (2015).

24. D.L. Guth, P. Zia. ACI Mater. J. 98, (2001). 